\title{
Clinical and Laboratory Predictors of Painful Vaso-Occlusive Crisis Among Sickle Cell Disease Patients: A Single-Center Study in Saudi Arabia
}

Ossama Zakaria ${ }^{1}$, Rayan A. Buhalim ${ }^{2}$, Fahad Almulhim ${ }^{2}$, Faisal A. Al Jabr ${ }^{2}$, Aqeel Alrashid ${ }^{2}$, Mohammed Almutairi $^{2}$

1. Department of Surgery, College of Medicine, Al-Ahsa, SAU 2. College of Medicine, King Faisal University, Al-Ahsa, SAU

Corresponding author: Rayan A. Buhalim, rayan.buhalim@gmail.com

\section{Abstract}

\section{Introduction}

Vaso-occlusive crisis (VOC) episodes are considered to be the cause of $95 \%$ of hospitalizations for sickle cell disease (SCD) patients. The frequency of VOC is significantly associated with higher or lower lactate dehydrogenase levels, higher hemoglobin concentration, higher white blood cell, and neutrophil count, and lower platelet counts. In this study, we highlighted the association and predictors of VOC episodes in Saudi Arabia.

\section{Methods}

This is a retrospective observational study that was conducted in a period from January 2018 to December 2019 which included patients who were admitted and treated as sickle cell disease patients were included in this study. Retrieved data included patients' age, sex, and other demographic data items as well as the clinical history of SCD. The patients were divided into two groups. Those patients who developed one or two VOC episodes in the period between 2018-2019 were considered mild in severity and patients who developed three or more VOC episodes in the period between 2018-2019 were categorized as moderate to severe.

\section{Results}

A total of ninety-four patients (58 males and 36 females) with a male to female ratio of 1.6 were included in this study. The prevalence of patients who had severe vaso-occlusive crisis was $39.4 \%$ while mild-moderate were detected among $60.6 \%$ of the patients. It was found that there was no significant difference between the frequency of vaso-occlusive crisis and all the hematological parameters (all $p>0.05$ ). It was found that the risk of having vaso-occlusive crisis for those patients who were admitted more than three times was 30 times higher than those patients who were admitted by three times or less [adjusted odds ratio $(\mathrm{AOR})=$ $30.081 ; 95 \%$ confidence interval $(\mathrm{CI})=8.204-110.3 ; \mathrm{p}<0.001)$ ].

Review began 04/30/2021 Review ended 05/02/2021 Published 05/12/2021

\section{(๑) Copyright 2021}

Zakaria et al. This is an open access article distributed under the terms of the Creative Commons Attribution License CC-BY 4.0., which permits unrestricted use, distribution, and reproduction in any medium, provided the original author and source are credited.

\section{Conclusion}

It was found that those patients who had three times VOC episodes in our studied period are more liable to have frequent episodes in the future which might necessitate urgent intervention for these patients.

Categories: Emergency Medicine, Family/General Practice, Hematology

Keywords: sickle cell anemia, saudi arabia, vaso-occlusive crisis, parameters, laboratory, profile, sickle cell disease, painful crisis, predictive, markers

\section{Introduction}

Sickle cell disease (SCD) is a hereditary hematological disorder that is inherited in an autosomal recessive manner [1]. It is classified under hemoglobinopathy disorders which are characterized by both intravascular and extravascular hemolysis due to a defect in the hemoglobin molecule of the erythrocytes [2-4]. SCD is caused by a single gene mutation, specifically point mutation, with resultant substitution of the glutamic acid with valine at position six of the beta-globin chain on chromosome 11 [3,5]. SCD can affect multiple organs due to the sickling of erythrocytes and resultant vaso-occlusion, along with hemolytic anemia [6]. Patients with SCD are at risk of various complications, including vaso-occlusive crises, stroke, proliferative retinopathy, acute chest syndrome, splenic atrophy with the consequence of more susceptibility to certain infections, nephropathy, gallstones, osteomyelitis, avascular necrosis (AVN), and more of other systemic complications $[2,3,6]$.

Vaso-occlusive crisis (VOC) episodes are considered to be the cause of 95\% of hospitalizations for SCD patients [7]. With certain precipitating factors, the hemoglobin $\mathrm{S}(\mathrm{HbS})$ starts to undergo polymerization and change the normal biconcave shape and flexibility of red blood cells (RBCs) into more sickled RBCs. The new 
sickled erythrocytes are more rigid and have lost their normal flow properties through the microcirculation, with the outcome of erythrocytes being aggregated as well as adhering to the vascular endothelium which causes vaso-occlusion $[2,3,8]$. This eventually results in ischemic tissue damage and inflammation causing severe pain $[9,10]$. As a result, VOC manifests as severe pain, especially in the back, joints, and extremities that lasts between three and seven days with the prodromal phase of one to two days $[8,11]$.

In general, the different complications of SCD have their own predictive values. For example, a splenic sequestration crisis has a higher recurrence rate if the spleen size is more than $3 \mathrm{~cm}$, reticulocyte count is greater than $300,000 / \mathrm{mm} 2$, and chronic pallor [12]. Moreover, in the case of AVN, the laboratory predictive value for the recurrence is a high steady-state platelet count [13]. However, the frequent VOC are clinical predictors for more symptomatic AVN [14].

In VOC, the frequency of painful crises is significantly associated with higher [15] or lower lactate dehydrogenase levels [16], higher hemoglobin concentration, higher white blood cell and neutrophils count $[16,17]$, and lower platelet counts [18]. It is also significantly correlated with pain-related gene variants [19], hospitalization rates [20], presence of thalassemia [16], and some SCD complications like nephropathy, stroke, and AVN [17]. To our knowledge, there are no studies in regards to clinical and laboratory predictors for painful VOC in Saudi Arabia. Thus, this study is the first to evaluate these predictors thoroughly.

\section{Materials And Methods}

\section{Study procedure}

This is a retrospective observational study that was conducted in a period from January 2018 to December 2019 for admitted patients in the same period.

This study was conducted from all patients' records to retrieve their data including sociodemographic data as well as the clinical presentations, hospital course including the laboratory findings, performed surgeries, and comorbidities.

The patients were divided into two groups according to the severity of the VOC in SCD patients defined as mild or moderate to severe as it was used in previous work [17]. Those patients who developed one or two VOC episodes in the period between 2018-2019 year were categorized as mild in severity. Patients who developed three or more VOC episodes in the period between 2018-2019 were categorized as moderate to severe.

Those who are Saudis, have SCD, previously admitted in the ward, males, and females, aged 18 and above were included in this study. However, others were excluded from this study.

\section{Statistical analysis}

The descriptive statistics were presented using numbers, percentages mean, and standard deviation, whenever appropriate. Univariate analyses were performed using Fischer Exact test as well as an independent t-test. Multivariate regression analysis was also conducted to determine the effect of the severe Vaso-occlusive crisis where the adjusted odds ratio, as well as $95 \%$ confidence interval, were also being reported. A P-value $\leqslant 0.05$ was considered statistically significant. The data analyses were performed using Statistical Packages for Social Sciences (SPSS) version 21 Armonk, NY: IBM Corporation.

\section{Ethical considerations}

Ethical approval was obtained from the ethical committee of the College of Medicine at King Faisal University. Also, consent and approval from the studied setting were obtained before the commencement of the study.

\section{Results}

We analyzed 94 patients who were diagnosed with sickle cell disease. As seen in Table 1, approximately $60 \%$ were in the younger age group ( $\leqslant 30$ years) with the majority were males $(61.7 \%)$ and more than half $(56.4 \%)$ were not married. We further observed $35.1 \%$ who were having associated comorbidities. However, $68.1 \%$ of the patients were admitted to the hospital three times or less during the last year. Furthermore, the prevalence of patients who had severe vaso-occlusive crisis was $39.4 \%$ while mild-moderate ones were detected among $60.6 \%$ of the patients. Likewise, the proportion of patients who underwent the operation was $53.2 \%$ while the proportion of patients who experienced complications was $68.1 \%$. In addition, all patients took medication for the management of the disease. 


\section{Cureus}

Study variables

N (\%)

Age group

$\leq 30$ years

55 (58.5\%)

$>30$ years

Gender

Male

Female

36 (38.3\%)

Marital status

Unmarried

Married

41 (43.6\%)

Comorbidities

Yes

No

Frequency of hospitalization

$\leq 3$ times

$>3$ times

$30(31.9 \%)$

Frequency of vaso-occlusive crisis

Mild-Moderate ( $<3$ times)

Severe ( $\geq 3$ times)

$37(39.4 \%)$

Operation

Yes

$50(53.2 \%)$

No

Medications

Yes

No

0

Complications

Yes

$64(68.1 \%)$

No

$30(31.9 \%)$

TABLE 1: Baseline characteristics of the patients $(n=94)$

SCD: Sickle Cell Disease; ACS: Acute Chest Syndrome.

Table 2 showed the mean values of different hematological parameters. It was found that the mean values of white blood cells, hemoglobin, platelet, Lactate dehydrogenase (LDH), total bilirubin, and direct bilirubin were $11.4,9.32,351.4,409.2,36.9$, and 22.7 , respectively while the mean values of hemoglobin electrophoresis, hemoglobin S, hemoglobin A2, hemoglobin A, and hemoglobin F were 1.85, 64.0, 2.87, 34.3 and 15.6, respectively. Additionally, the mean number of blood transfusions was 3.81 . 


\section{Cureus}

\section{Variables}

White blood count

Hemoglobin

Platelet

Lactate dehydrogenase

Total Bilirubin

Direct Bilirubin

Hemoglobin Electrophoresis

Hemoglobin S

Hemoglobin A2

Hemoglobin A

Hemoglobin F

Number of blood transfusion
Mean \pm SD

$11.4 \pm 5.77$

$9.32 \pm 1.75$

$351.4 \pm 439.0$

$409.2 \pm 421.2$

$36.9 \pm 43.8$

$22.7 \pm 60.8$

$1.85 \pm 0.36$

$64.0 \pm 24.1$

$2.87 \pm 0.91$

$34.3 \pm 38.4$

$15.6 \pm 10.0$

$3.81 \pm 2.49$

TABLE 2: Hematological parameters $(n=94)$

Figure 1 presented the type of procedure done to the patients. It was revealed that the most commonly performed procedure was cholecystectomy (36.2\%), followed by splenectomy (12.8\%) and hip replacement (3.2\%).

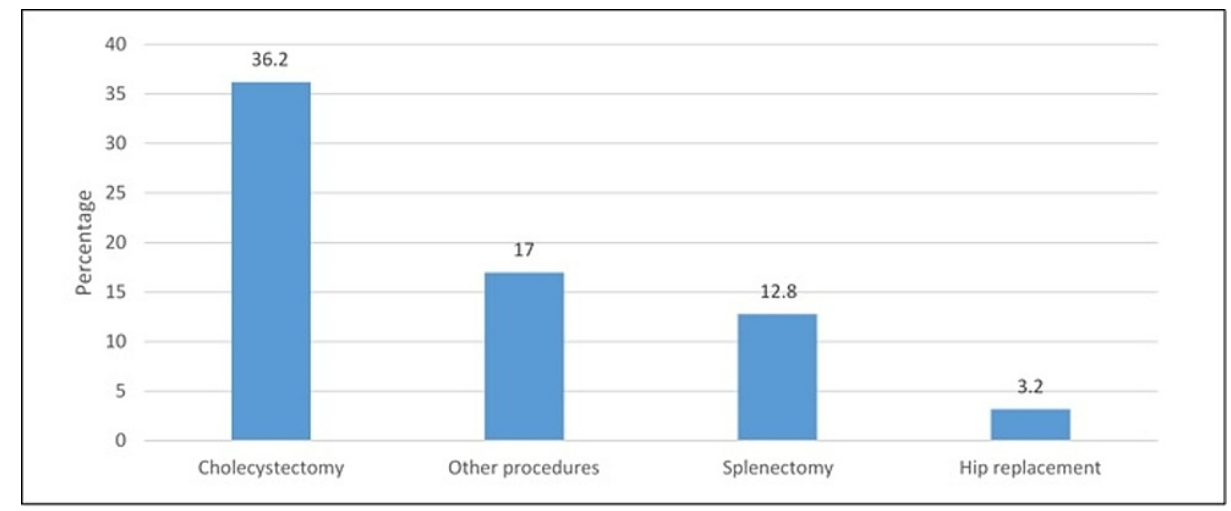

FIGURE 1: Type of procedure performed to patients

Figure 2 depicted the prescribed medications to patients. It was found that the most commonly prescribed medication was analgesics (100\%), followed by folic acid (95.7\%) and narcotics (91.5\%). 


\section{Cureus}

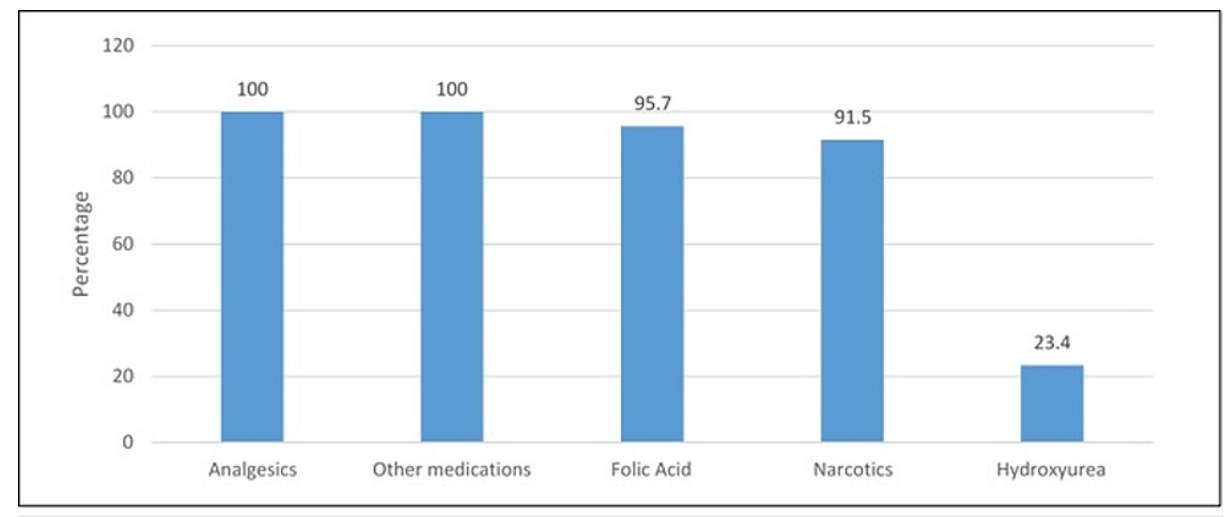

FIGURE 2: Type of prescribed medications

In Figure 3, the most frequently mentioned complication was a hemolytic crisis (30.9\%) and acute chest syndrome (30.9\%) followed by gallstone (26.6\%) while the least of them was an aplastic crisis (1.1\%).

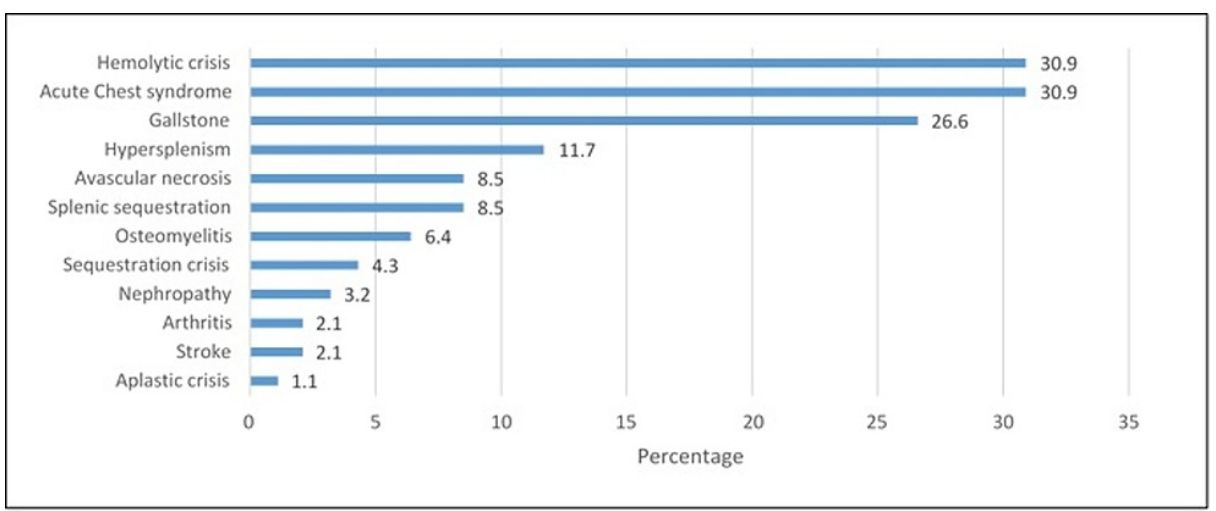

FIGURE 3: Complications

In univariate analysis of the vaso-occlusive crisis, it was revealed that frequency of hospitalization $(\mathrm{p}<0.001)$, other procedures $(\mathrm{p}=0.050)$, narcotics $(\mathrm{p}=0.020)$, hydroxyurea $(\mathrm{p}=0.045)$, and avascular necrosis $(\mathrm{p}<0.001)$ were the factors associated with vaso-occlusive crisis (Table 3).

\section{Factor}

Age group

$\leq 30$ years

$>30$ years

Gender

Male

Female

Marital status

Unmarried

Married

Comorbidities

Yes

\section{Frequency of Vaso-occlusive Crisis}

Severe $(\geq 3) N(\%){ }^{(n=37)}$

Mild-moderate $(<3) \mathrm{N}(\%){ }^{(\mathrm{n}=57)}$

$32(56.1 \%)$

$25(43.9 \%)$

14 (37.8\%)

$23(62.2 \%)$

$14(37.8 \%)$

$35(61.4 \%)$

22 (38.6\%)

$23(62.2 \%)$

$30(52.6 \%)$

$27(47.4 \%)$

$14(37.8 \%)$

$14(37.8 \%)$
0.401

P-value ${ }^{\S}$

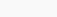




\section{Cureus}

No

$23(62.2 \%)$

$38(66.7 \%)$

Frequency of hospitalization

$\leq 3$ times

$11(29.7 \%)$

$53(93.0 \%)$

$>3$ times

$26(70.3 \%)$

$04(07.0 \%)$

Operation

$21(56.8 \%)$

$29(50.9 \%)$

$<0.001$ **

Cholecystectomy

$15(40.5 \%)$

$19(33.3 \%)$

0.673

Splenectomy

$04(10.8 \%)$

$08(14.0 \%)$

0.515

Hip replacement

$01(02.7 \%)$

$02(03.5 \%)$

0.759

Other procedures

$10(27.0 \%)$

$06(10.5 \%)$

1.000

Narcotics

37 (100\%)

$49(86.0 \%)$

0.050 **

Folic Acid

35 (94.6\%)

Hydroxyurea

$13(35.1 \%)$

$55(96.5 \%)$

0.020 **

Complication

$27(73.0 \%)$

$09(15.8 \%)$

0.645

37 (64.9\%)

$0.045^{\text {** }}$

Acute Chest syndrome

$10(27.0 \%)$

$19(33.3 \%)$

0.499

Splenic Sequestration

$04(10.8 \%)$

$04(07.0 \%)$

0.649

Sequestration crisis

0

$04(07.0 \%)$

0.708

Hemolytic crisis

$14(37.8 \%)$

$15(26.3 \%)$

0.151

$01(02.7 \%)$

0

0.260

Aplastic crisis

$13(35.1 \%)$

$12(21.1 \%)$

0.394

Gall stone

$01(02.7 \%)$

$01(01.8 \%)$

0.156

Stroke

$08(21.6 \%)$

0

1.000

Avascular necrosis

$01(02.7 \%)$

$02(05.4 \%)$

$02(03.5 \%)$

$<0.001$ **

Nephropathy

$01(02.7 \%)$

$04(07.0 \%)$

1.000

Osteomyelitis

$03(08.1 \%)$

$01(01.8 \%)$

1.000

Arthritis

$08(14.0 \%)$

1.000

0.518

TABLE 3: Univariate analysis to determine the factors associated with vaso-occlusive crisis $(n=94)$

§ P-value has been calculated using Fischer Exact test.

** Significant at $\mathrm{p} \leq 0.05$ level.

In the comparison between vaso-occlusive crisis and hematological parameters. It was found that there was no significant difference between the frequency of vaso-occlusive crisis and all the hematological parameters (all p>0.05) (Table 4). 


\section{Cureus}

\begin{tabular}{|c|c|c|c|}
\hline \multirow{2}{*}{ Parameters } & \multicolumn{2}{|c|}{ Frequency of Vaso-occlusive Crisis } & \multirow{2}{*}{ P-value ${ }^{\ddagger}$} \\
\hline & Severe $(\geq 3)$ Mean \pm SD & Mild-moderate $(<3)$ Mean \pm SD & \\
\hline White blood count & $10.8 \pm 4.41$ & $11.8 \pm 6.57$ & 0.397 \\
\hline Hemoglobin & $9.03 \pm 1.57$ & $9.52 \pm 1.86$ & 0.187 \\
\hline Platelet & $412.2 \pm 629.0$ & $306.4 \pm 206.8$ & 0.269 \\
\hline Lactate dehydrogenase & $499.9 \pm 447.3$ & $322.0 \pm 382.9$ & 0.133 \\
\hline Total Bilirubin & $37.2 \pm 36.3$ & $36.8 \pm 49.4$ & 0.973 \\
\hline Direct Bilirubin & $25.6 \pm 76.9$ & $20.3 \pm 44.2$ & 0.738 \\
\hline Hemoglobin Electrophoresis & $1.84 \pm 0.37$ & $1.86 \pm 0.35$ & 0.775 \\
\hline Hemoglobin S & $59.3 \pm 23.4$ & $68.0 \pm 25.8$ & 0.538 \\
\hline Hemoglobin A2 & $2.50 \pm 0.72$ & $3.10 \pm 0.98$ & 0.260 \\
\hline Hemoglobin A & $54.4 \pm 41.9$ & $24.2 \pm 38.2$ & 0.424 \\
\hline Hemoglobin F & $18.2 \pm 13.8$ & $14.0 \pm 7.45$ & 0.489 \\
\hline Number of blood transfusion & $4.08 \pm 2.45$ & $3.59 \pm 2.55$ & 0.470 \\
\hline
\end{tabular}

\section{TABLE 4: Comparison between vaso-occlusive crisis and hematological parameters $(n=94)$}

$\S \mathrm{P}$-value has been calculated using Fischer Exact test. $\ddagger$ P-value has been calculated using Independent $\mathrm{t}$-test.

** Significant at $\mathrm{p} \leq 0.05$ level.

When conducting multivariate regression analysis to determine the effect of severe vaso-occlusive crisis in relation to the selected baseline characteristics of the patients, we have learned that the risk of having vasoocclusive crisis for those patients who were admitted more than three times was 30 times higher than those patients who were admitted by three times or less (AOR=30.081; 95\% CI=8.204 - 110.3; $<<0.001)$. Other variables included in the model such as other procedures, narcotics, and hydroxyurea were observed to have no significant effect with vaso-occlusive after adjustment to regression model (Table 5). 


\section{Cureus}

\begin{tabular}{|c|c|c|c|}
\hline Factor & AOR & $95 \% \mathrm{Cl}$ & P-value \\
\hline \multicolumn{4}{|c|}{ Frequency of hospitalization } \\
\hline$\leq 3$ times & Ref & & \\
\hline$>3$ times & 30.081 & $8.204-110.3$ & $<0.001$ ** \\
\hline \multicolumn{4}{|c|}{ Other procedures } \\
\hline Yes & 0.283 & $0.039-2.053$ & 0.212 \\
\hline No & Ref & & \\
\hline \multicolumn{4}{|l|}{ Narcotics } \\
\hline Yes & 2.990 & $0.627-14.270$ & 0.170 \\
\hline No & Ref & & \\
\hline \multicolumn{4}{|c|}{ Hydroxyurea } \\
\hline Yes & 3.411 & $0.738-15.775$ & 0.116 \\
\hline No & Ref & & \\
\hline
\end{tabular}

TABLE 5: Multivariate regression analysis to determine the effect of severe Vaso-occlusive crisis $(n=94)$

AOR: Adjusted Odds Ratio; Cl: Confidence Interval. *^ Significant at $\mathrm{p} \leq 0.05$ level.

\section{Discussion}

Sickle cell disease (SCD) is one the most prevalent hematological diseases in Saudi Arabia [21], in which it is associated with several complications such as vaso-occlusive crises, avascular necrosis (AVN), gallstones, acute chest syndrome, splenic atrophy, and others $[2,3,6]$. Several studies showed that various clinical and laboratory findings could be associated with the frequency of their complications. However, they were not conducted in Saudi Arabia. Thus, in this study, we highlighted this issue to make it a base for further studies.

As demonstrated in Table 1, the majority of our patients were less than 30 years of age, which is similar to a previous study from the literature [17]. As observed in Table 3, the most common surgical operation for SCD patients is cholecystectomy, which is consistent with a previous study [22]. This is because these patients tend to have chronic hemolysis which causes the formation of pigment gall stones and necessitates cholecystectomy. However, a previous study stated that most of the included patients were hospitalized less than three times which is similar to our findings in Table 1 . We also support the findings in which hemolytic crisis is the most common complication among SCD patients [23].

As demonstrated in Table 3, it is revealed in our study that several factors are significantly associated with the vaso-occlusive crisis severity such as increased number of hospitalizations, number of the administered narcotic analgesia, taking hydroxyurea, and AVN. Similarly, a previously conducted study supports our findings which is, an increased number of vaso-occlusive events is significantly associated with an increased number of hospitalizations as well as AVN [17], and another study supports the finding of the AVN [14]. This similarity of the results between the studies suggests serious consideration of these factors as predictors of further vaso-occlusive attacks. Moreover, further studies are needed to confirm and explore the reason behind these findings and to put the required preventive measures.

Previous studies have shown that there are several significant predictors for the severity of the vasoocclusive crisis such as higher white blood cell count, higher lactate dehydrogenase, higher hemoglobin level, higher steady platelet count, alpha-thalassemia trait, hemoglobin SS phenotype $[8,15,17,18,20]$. On the other hand, there was no significant difference between the frequency of vaso-occlusive crisis and all the hematological parameters included in our study as seen in Table 2. Furthermore, another study showed similar results to our study [14].

Our study has significantly shown that patients who have been admitted more than three times have a 30 times higher risk for severe vaso-occlusive crisis compared to patients who were admitted three times or less. Also, one study showed that patients with frequent hospital readmissions because of vaso-occlusive crisis have poor outcomes, prognosis, and demand more care and monitoring [7]. 


\section{Limitations}

Besides the limitation of being a low sample size study, the authors recommend that future prospective studies should be conducted to enhance the quality of data.

\section{Conclusions}

Despite the authors could not find a significant association between VOC episodes and the hematological parameters, the study concluded that those patients who had three times VOC episodes are more liable to have frequent episodes in the future. This study supports the earlier use of hydroxyurea to avoid such complications of frequent crises. However, a larger sample size with prospective studies is recommended to be done in the future.

\section{Additional Information \\ Disclosures}

Human subjects: Consent was obtained or waived by all participants in this study. College of Medicine, King Faisal University issued approval 2020 - 10 - 10. Animal subjects: All authors have confirmed that this study did not involve animal subjects or tissue. Conflicts of interest: In compliance with the ICMJE uniform disclosure form, all authors declare the following: Payment/services info: All authors have declared that no financial support was received from any organization for the submitted work. Financial relationships: All authors have declared that they have no financial relationships at present or within the previous three years with any organizations that might have an interest in the submitted work. Other relationships: All authors have declared that there are no other relationships or activities that could appear to have influenced the submitted work.

\section{References}

1. John N: A review of clinical profile in sickle cell traits . Oman Med J. 2010, 25:3-8. 10.5001/omj.2010.2

2. Rees DC, Williams TN, Gladwin MT: Sickle-cell disease. Lancet. 2010, 376:2018-31. 10.1016/S01406736(10)61029-X

3. Kato GJ, Piel FB, Reid CD, et al.: Sickle cell disease. Nat Rev Dis Primers. 2018, 4:18010. 10.1038/nrdp.2018.10

4. Ware RE, de Montalembert M, Tshilolo L, Abboud MR: Sickle cell disease. Lancet. 2017, 390:311-23. 10.1016/S0140-6736(17)30193-9

5. Wilson M, Forsyth P, Whiteside J: Haemoglobinopathy and sickle cell disease . BJA Educ. 2010, 1:24-8. 10.1093/bjaceaccp/mkp038

6. Piel FB, Steinberg MH, Rees DC: Sickle cell disease. N Engl J Med. 2017, 376:1561-73. 10.1056/NEJMra1510865

7. Ballas SK, Lusardi M: Hospital readmission for adult acute sickle cell painful episodes: frequency, etiology, and prognostic significance. Am J Hematol. 2005, 79:17-25. 10.1002/ajh.20336

8. Darbari DS, Sheehan VA, Ballas SK: The vaso-occlusive pain crisis in sickle cell disease: definition, pathophysiology, and management. Eur J Haematol. 2020, 105:237-46. 10.1111/ejh.13430

9. Solovey A, Kollander R, Milbauer LC, Abdulla F, Chen Y, Kelm RJ Jr, Hebbel RP: Endothelial nitric oxide synthase and nitric oxide regulate endothelial tissue factor expression in vivo in the sickle transgenic mouse. Am J Hematol. 2010, 85:41-5. 10.1002/ajh.21582

10. Manwani D, Frenette PS: Vaso-occlusion in sickle cell disease: pathophysiology and novel targeted therapies. Blood. 2013, 122:3892-8. 10.1182/blood-2013-05-498311

11. Ballas SK, Gupta K, Adams-Graves P: Sickle cell pain: a critical reappraisal. Blood. 2012, 120:3647-56. 10.1182/blood-2012-04-383430

12. Ben Khaled M, Ouederni M, Mankai Y, et al.: Prevalence and predictive factors of splenic sequestration crisis among 423 pediatric patients with sickle cell disease in Tunisia. Blood Cells Mol Dis. 2020, 80:102374. 10.1016/j.bcmd.2019.102374

13. Madu AJ, Madu AK, Umar GK, Ibekwe K, Duru A, Ugwu AO: Avascular necrosis in sickle cell (homozygous S) patients: predictive clinical and laboratory indices. Niger J Clin Pract. 2014, 17:86-9. 10.4103/11193077.122852

14. Mesleh Shayeb A, Smeltzer MP, Kaste SC, Brown A, Estepp JH, Nottage KA: Vaso-occlusive crisis as a predictor of symptomatic avascular necrosis in children with sickle cell disease. Pediatr Blood Cancer. 2018, 65:e27435. 10.1002/pbc.27435

15. Stankovic Stojanovic K, Steichen O, Lefevre G, et al.: High lactate dehydrogenase levels at admission for painful vaso-occlusive crisis is associated with severe outcome in adult SCD patients. Clin Biochem. 2012, 45:1578-82. 10.1016/j.clinbiochem.2012.07.114

16. Darbari DS, Onyekwere O, Nouraie M, et al.: Markers of severe vaso-occlusive painful episode frequency in children and adolescents with sickle cell anemia. J Pediatr. 2012, 160:286-90. 10.1016/j.jpeds.2011.07.018

17. Ugwu AO, Ibegbulam OG, Nwagha TU, Madu AJ, Ocheni S, Okpala I: Clinical and laboratory predictors of frequency of painful crises among sickle cell anaemia patients in nigeria. J Clin Diagn Res. 2017, 11:EC22-5. 10.7860/TCDR/2017/26446.10042

18. Shanley LA, Ebeling M, Titus MO: Changes in platelet count as a predictive tool in sickle cell acute vasoocclusive crises: a pediatric study. Clin Pediatr (Phila). 2011, 50:657-61. 10.1177/0009922811399347

19. Wonkam A, Mnika K, Ngo Bitoungui VJ, Chetcha Chemegni B, Chimusa ER, Dandara C, Kengne AP: Clinical and genetic factors are associated with pain and hospitalisation rates in sickle cell anaemia in Cameroon. $\mathrm{Br}$ J Haematol. 2018, 180:134-46. 10.1111/bjh.15011 


\section{Cureus}

20. Adewoyin AS, Ezenwenyi IP, Nwogoh B, Awodu OA: One year retrospective review of Bone pain crisis among adult sickle cell disease patients in benin city, nigeria. IOSR-JDM. 2015, 14:56-62. 10.9790/085314855662

21. Jastaniah W: Epidemiology of sickle cell disease in Saudi Arabia . Ann Saudi Med. 2011, 31:289-93. $10.4103 / 0256-4947.81540$

22. Adam S, Jonassaint J, Kruger H, et al.: Surgical and obstetric outcomes in adults with sickle cell disease . Am J Med. 2008, 121:916-21. 10.1016/j.amjmed.2008.04.040

23. Saidi H, Smart LR, Kamugisha E, Ambrose EE, Soka D, Peck RN, Makani J: Complications of sickle cell anaemia in children in Northwestern Tanzania. Hematology. 2016, 21:248-56.

$10.1080 / 10245332.2015 .1101976$ 